\title{
A Novel Parallel Current-sharing Control Method of Switch Power Supply
}

\author{
Chao $\mathrm{Wu}$, Bingjuan Lu and Yuwang Ge*
}

Department of Electrical Engineering and Automation, Luoyang Institute of Science and Technology, Henan, China, 471023

\begin{abstract}
A novel parallel current-sharing control method of switch power supply is proposed, on the basis of a detailed analysis of several common parallel current-sharing control methods and recent related patents. Only the current of switch power modules with maximum and minimum output current will be regulated, which is selected by the extreme current selection circuit in this method. Four cases with different extremum situation are discussed, and in each case, principles and equations are given. Finally the current-sharing control of switch power supply parallel system is realized. Experimental results show that the current-sharing method is reasonable and effective.
\end{abstract}

Keywords: Current-sharing control, extreme current selection circuit, switch power supply.

\section{INTRODUCTION}

With the development of power electronics technology, switch power supply has widely emerged in fields of computer, industry and communication. Parallel architecture is commonly used, which combines multiple power modules into high-power supply, that is, distributed power, to improve output and reliability. The modules in distributed power supply are independent and flexible, whose capacity can be expanded according to load. The standardized module system reduces volume, weight as well as the cost.

In distributed power generation, inconsistency between parallel modules may occur. In this case, power modules with good external characteristics may sustain more current or even result in overload which greatly reduces their service lives. Current-sharing control is necessary for parallel power system. It guarantees current balance and reasonable allocation between parallel power modules and prevent certain modules from overload. In this paper, after reviewing several common parallel current-sharing control strategies, a novel strategy is proposed. It selects the maximum and minimum output switch power supply modules with extremum current selection circuit and regulates the current through them. Experiments indicate its good effectiveness and reasonableness.

\section{COMMON PARALLEL CURRENT-SHARING CONTROL STRATEGIES}

In order to realize uniform current distribution among parallel power modules, many current-sharing control strategies have been raised and developed [1]. The most common methods are external characteristics drooping (output impedance method), master/slave module setting and active current-sharing.

\subsection{External Characteristic Drooping (Output Imped- ance Method)}

External characteristic drooping [2] regulates output impedance to achieve current sharing. Every module in parallel system works independently, whose current is determined by its external characteristics and output impedance. This strategy is simple without any dedicated equipment for its openloop character. However the method is not accurate enough, so individual changes has to be performed. Besides, power differences among parallel modules will induce unbalanced current among modules.

\subsection{Master/Slave Module Setting}

Master/slave module setting method [3] selects one of the parallel modules as master module, while others as slave modules. Current of master module is compared with feedback signal, and transmits the difference to control circuits of all modules (including master and slave) to regulate the output current of modules. Master/slave module setting method is closed-loop without any dedicated control element, so its accuracy is higher. However, communications is required among modules, which makes complex connection. Furthermore, if master module fails, the whole power system will crash, and it is not suitable for redundant parallel system.

\subsection{Active Current-Sharing}

Active current-sharing includes auto average current sharing and auto maximum current sharing [4].

Auto average current sharing connects current amplifier output of all parallel power modules to public bus through resistor $\mathrm{R}$, which is called current-sharing bus. Its block diagram is shown in Fig. (1). As we can see, this topology is not complex with acceptable accuracy; however, if currentsharing bus is short or any module connected with bus fails, the average voltage of bus as well as other module is reduced. So this method is not suitable for parallel power sys- 


\section{Block Diagram}

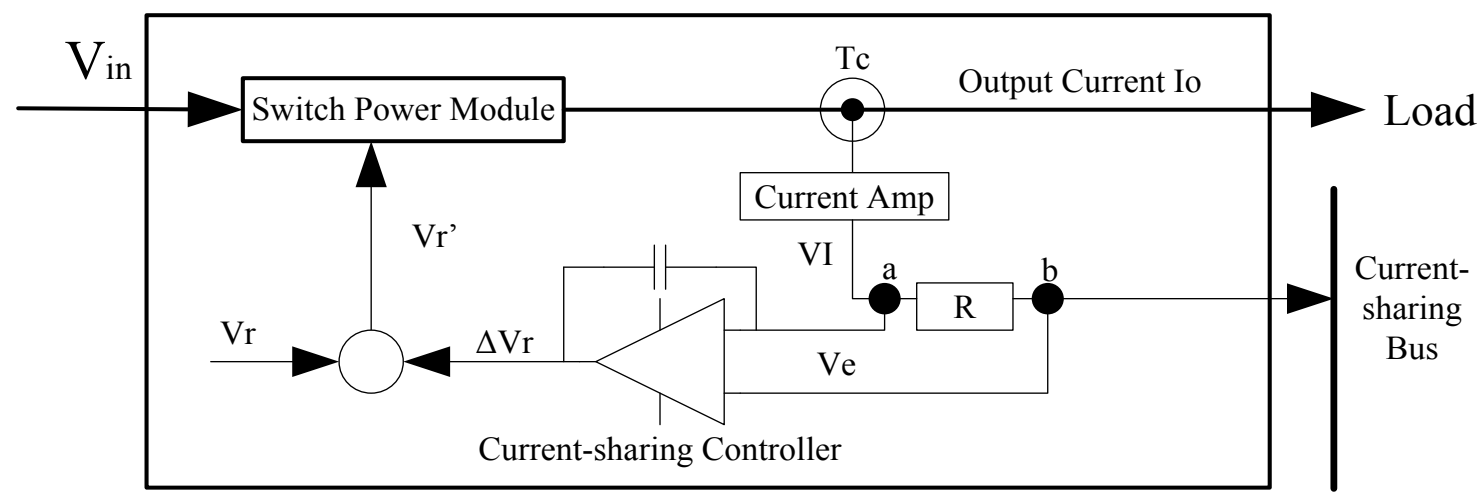

Fig. (1). Block diagram of auto average current-sharing method.

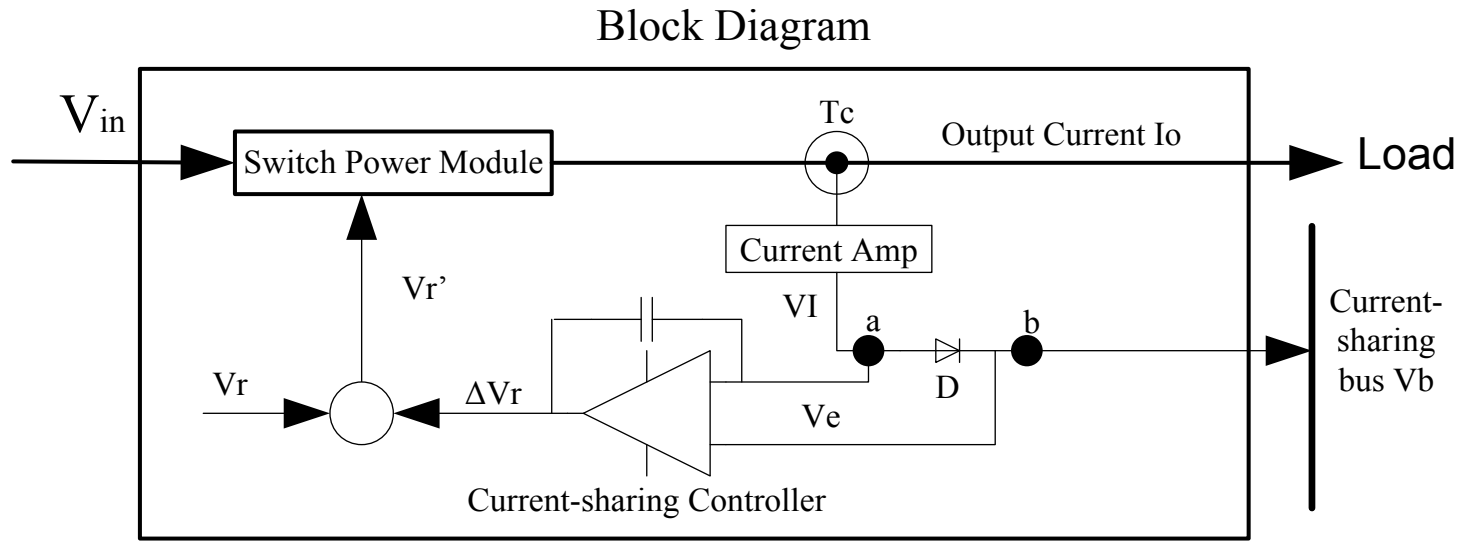

Fig. (2). Block diagram of auto maximum current-sharing method.

tem with auto-withdrawal mechanism when power module failing.

Auto maximum current sharing is a dynamic method which determines master module automatically according to maximum output current. The differences between master module and slave modules are regulated respectively to regulate the current distribution, so it's called "auto master/slave control method". Its block diagram is shown in Fig. (2). The parallel power sources are not isolated but connected through a current-sharing bus. It provides a current reference to every module and regulates output current according to the reference so that accurate current-sharing is achieved among parallel modules. This topology is proved to be a good redundant system, avoiding system performance degradation due to one single module fault. However, master/slave modules are switching all the time, and it will result in low frequency oscillation at output current; besides, power modules regulate the output according to "maximum current", it means all power modules except master will increase output current. With constant load, current increments among slave modules are greater than current reduction of master module, which results in output voltage being higher than rated voltage (known as "overvoltage"). "Overvoltage" may have some bad influence on safety, reliability and stability of power system and it will reduce the system dynamic response.

\subsection{Other Advanced Current-Sharing Methods}

There are other common methods such as thermal stress auto method which monitors the temperature to achieve current-sharing and external controller method which adds a dedicated controller for management and control. As well as the methods mentioned above, we can see that traditional current-sharing methods have their own merits as well as their own demerits. So, nowadays researchers have focused on novel current-sharing topology to improve performance. One of the most famous is named "Control circuit and method of parallel DC switch power source with double currentsharing buses" [5]. The inventor also raised 4 current-sharing method based on intelligent controller (CPU) (shown in Fig. 3). The system proposed depends greatly upon processor and software programming, which increases the total cost. Also we listed the current-sharing method proposed to see if it is possible to be improved:

1. Current-sharing based on minimum current: processor of every power module calculates minimum current according to signal from the first and second current-sharing bus. Take the minimum output current as reference, every power module but the module with minimum output will reduce its current which results in current decrement of all current modules being greater than the current increment. It means 


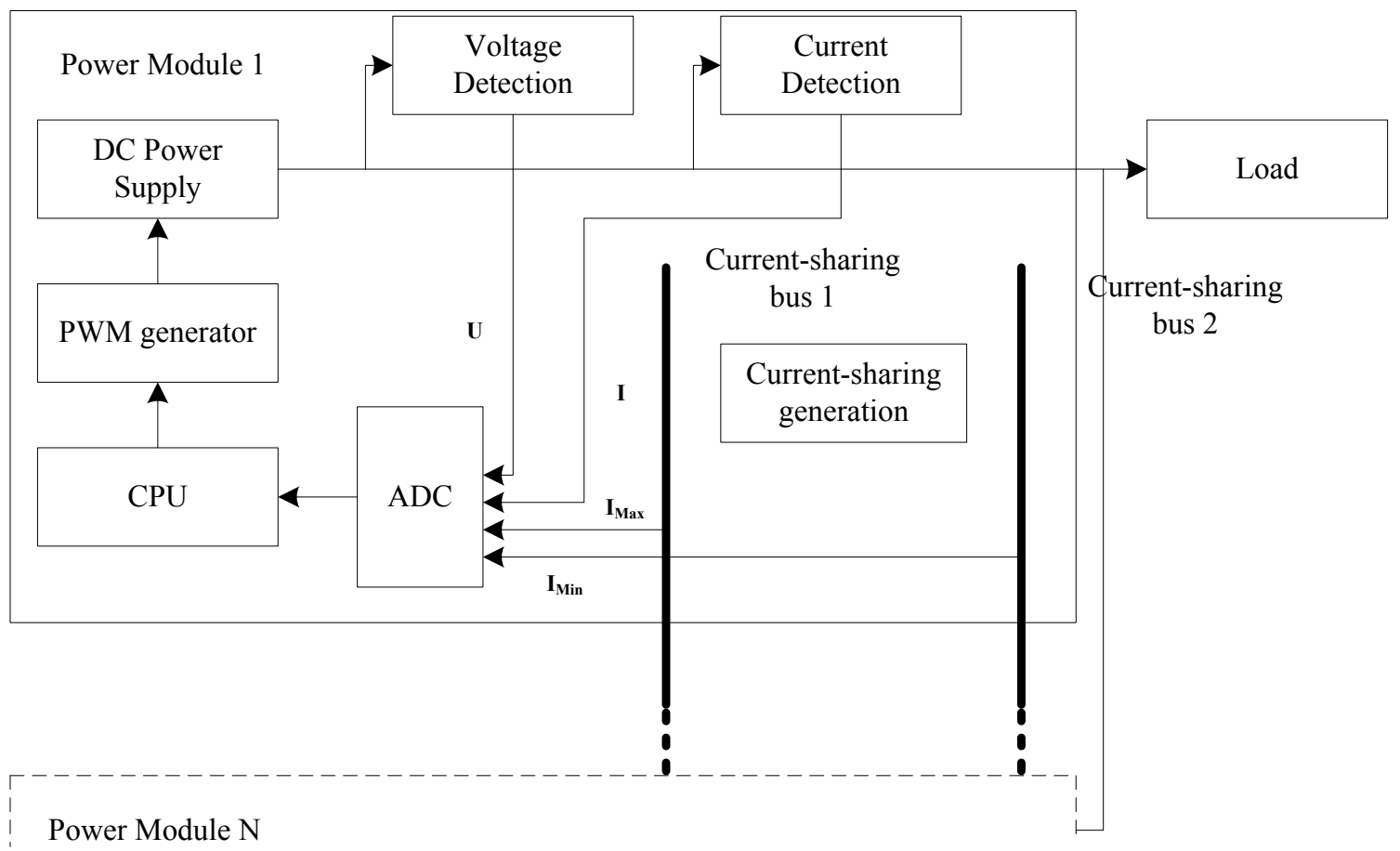

Fig. (3). Control circuit and method of parallel DC switch power source with double current-sharing buses.

total output of power modules is smaller than the rated voltage, named as "undervoltage". "Undervoltage" cannot fulfill the power requirement of load, and increases regulating frequency of system passively.

2. Simplified minimum current control method: CPU of every module compares its own output current signal with maximum current to see if the module is the module with maximum current. Only the module with maximum current will be regulated, referred as minimum current, while other modules won't be involved. Since the output current of maximum module is reduced, in case of constant load, current of other modules will increase so that some module will replace as the maximum module and be regulated. In this way, the regulating frequency is much higher than theoretical value. Moreover, if there are more than one modules with maximum output current, they will be regulated simultaneously by minimum current and other modules may be influenced even strongly, which increases regulating frequency and affects dynamic response of system.

3. Current-sharing based on middle current: CPU calculates a middle current (not average current) according to the difference between maximum current and minimum current, and takes the middle current as reference to regulate outputs. Modules with lower current will increase their currents while modules with higher current will decrease their currents. However, every module in system will be regulated so regulating frequency is much greater than (1) and (2).

4. Simplified middle current-sharing method: CPU of every module compares its own output current signal with maximum and minimum current to see if the module is the module with maximum or minimum current. Only the module with maximum or minimum current will be regulated, referred as middle current calculated in (3), while other modules won't be involved. Since the output current of maximum module is reduced and minimum module is increased, in case of constant load, current of other modules will change so that some module will replace as the maximum and minimum module and be regulated. In theory, only two modules are regulated at the same time and frequency may be low, but the two modules themselves are switching all the time. Besides, they're regulated according to middle value rather than average value. All these facts increase theoretical frequency. If there are more than one module with maximum or minimum output currents, and current decrement of all current modules may not be equal to the current increment due to the complexity of system. So "overvoltage" or "undervoltage" will occur.

Other researchers such as in [6] proposed a power supply with a current-sharing function using a bus terminal as a current-sharing control interface. The power circuit provides an output voltage and an output current to an output terminal which generates a current-sense signal according to the output current. A feedback control circuit controls the power circuit according to the output of the power-supply apparatus. A current-sharing unit generates and outputs a bus signal to the bus terminal according to the current-sense signal [7]. Declared a power system with a combination of active current sharing and droop current sharing (shown in Fig. 4). The power system includes a system load and multiple power supplies connected with each other and connected to the system load. Active current sharing circuit selects its operation mode depending on whether the load current is higher than a first current set point, while droop current 


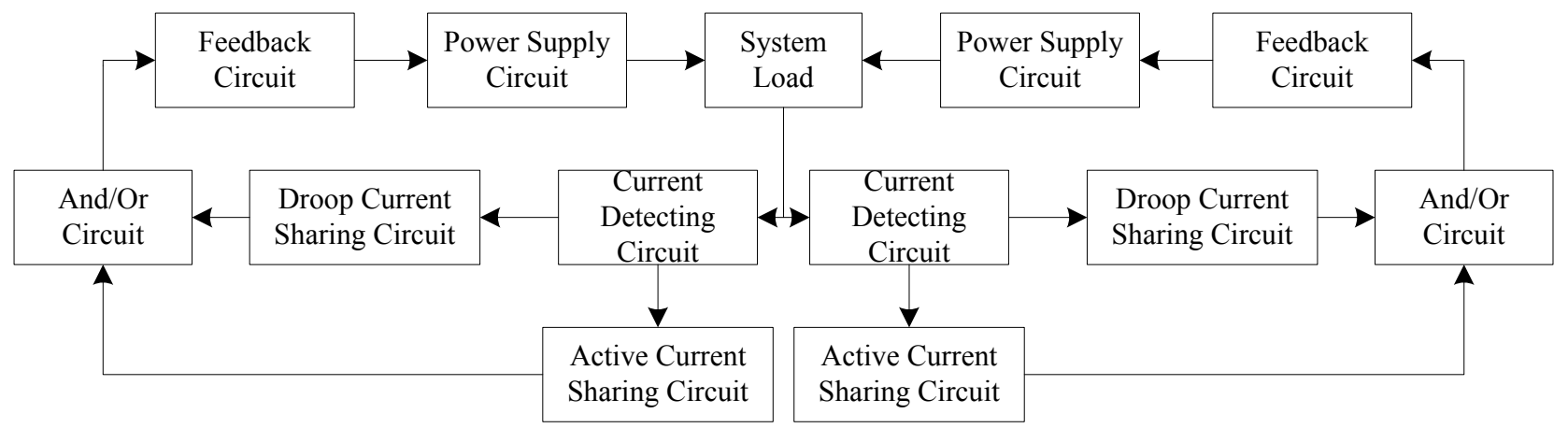

Fig. (4). Power system with combination of active current-sharing and droop current sharing.
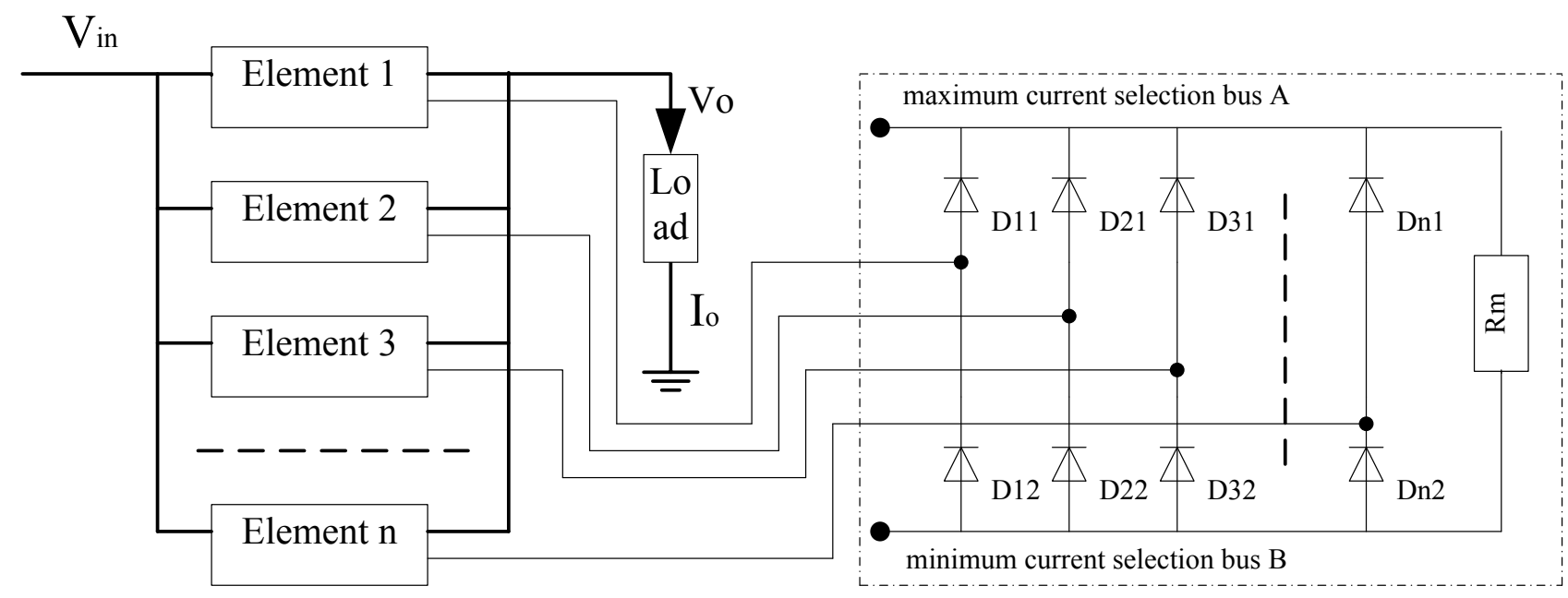

extreme current selection circuit

Fig. (5). Block diagram of the novel current-sharing method.

sharing circuit depends on whether the load current is higher than a second current set point. [8] Raised the architecture with multiple channels. Each channel has a current sharing controller that is coupled to a shared current and voltage signal bus. In recent years, many researchers have achieved their goals as current-sharing has been granted patents [9$12]$.

Reasonable parallel control topology becomes a key issue for improving system reliability and capacity. While through the analysis above, we find that much work has been carried out in improving current-sharing. However, with the increasing requirement towards reliability, dynamic response, capacity redundancy and real-time character, we need to propose a novel and more rational control method [13-15].

\section{A NOVEL CURRENT-SHARING METHOD}

To improve the performance of parallel switch power supply, a novel current-sharing method is proposed in this paper, whose diagram is shown in Fig. (5).

Every element of parallel switch power supply consists of power module and control circuit, whose output current represented by voltage signal is connected to one couple of serial diode with extremum current selection circuit. So, $n$ elements require $\mathrm{n}$ couples of serial diodes. Upper arms (Common cathode) of the diodes constitute maximum current selection bus, while lower arms (Common anode) constitute minimum current selection bus. The two buses are connected through bus isolation resistor $R_{m}$.

Extremum current selection circuit consisted of $n$ couples of diodes work as n-phase circuit. Only the voltage (representing current) from maximum current output module can reach maximum current selection bus and the voltage from minimum current output module can reach minimum current selection bus. Current induced by the voltage difference between the two buses forms deviation voltage $V_{e}$ across isolation resistor $R_{m}$, which forms new reference voltage $V_{r}$ ' with initial reference voltage $V_{r}$. The new value controls power module to realize current-sharing. Block diagram of the novel system is shown in Fig. (6).

Running/fault indicator of power module is provided in this current-sharing topology for redundancy architecture so that if one of the power modules fails, the system will not crash. In Fig. (6), if one of the power modules fails, output voltage of current detection circuit falls to zero and the optocoupler is disconnected, which makes relay lose power. Then faulty module is isolated from system and fault indicator is turned on. In this way, system reliability is improved. 
Block Diagram

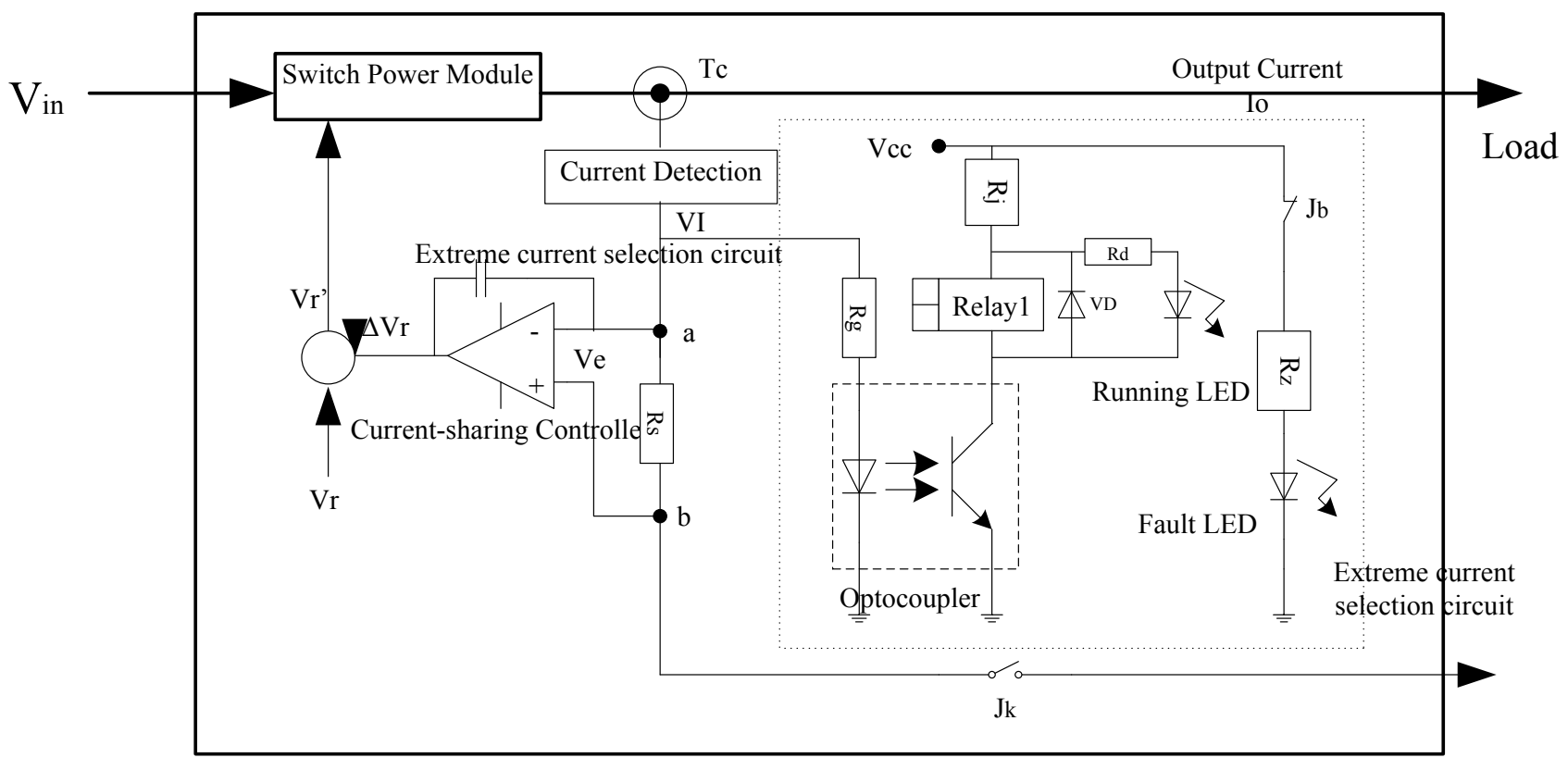

Fig. (6). Block diagram of basic element.

\section{MECHANISM OF THE NOVEL CURRENT- SHARING METHOD}

This current-sharing strategy obtains voltage values $V_{I I}$, $V_{I 2} \ldots V_{I n}$, which represent the current from every module, through current detection circuits, and transmits the extremum value to selection circuit. The buses will get the elements with maximum and minimum current outputs, represented as $V_{I \max }$ and $V_{I \min }$. The difference between $V_{I \max }$ and $V_{I_{-} \min }$ forms current through $R_{s}$ and $R_{m}$, and the voltage required by maximum and minimum current modules $V_{e-\max }=$ $U_{a b}>0$ and $V_{e-\min }=U_{a b}<0$ can be calculated. The calculation process should be differentiated into four categories and handled accordingly:

(1) $i=1, j=1$ : In this case, only one maximum and minimum output current modules exist, whose equivalent circuit is shown in Fig. (7a). We get:

$\frac{V_{e_{-} \max }}{R_{s}}=\frac{-V_{e_{-} \min }}{R_{s}} \Rightarrow V_{e_{-} \max }=-V_{e_{-} \min }$

(2) $i=1, j>1:$ In this case, one maximum and $\mathrm{j}$ minimum output current modules exist, whose equivalent circuit is shown in Fig. (7b). We get:

$\frac{V_{e \_ \text {max }}}{R_{s}}=-\frac{V_{e_{\_} \text {min } 11}}{R_{s}}-\frac{V_{e_{\_} \text {min_ } 2}}{R_{s}}-\ldots-\frac{V_{e_{\_} \min \_j}}{R_{s}}$

$V_{e_{-} \max }=-V_{e_{-} \text {min } \_1}-V_{e_{-} \min \_2}-\ldots-V_{e_{-} \min _{-} j}$

$V_{e_{-} \text {max }}>-V_{e_{-} \text {min } \_1}=-V_{e_{-} \text {min_ } 2}=\ldots=-V_{e_{-} \text {min_ } j}$

(3) $i>1, j=1$ : In this case, one minimum and i maximum output current modules exist, whose equivalent circuit is shown in Fig. (7c). We get:

$$
\begin{aligned}
& \frac{-V_{e_{-} \min }}{R_{s}}=\frac{V_{e_{-} \max 1}}{R_{s}}+\frac{V_{e_{-} \max \_2}}{R_{s}}+\ldots+\frac{V_{e_{-} \max i}}{R_{s}} \\
& -V_{e_{-} \min }=V_{e_{-} \max _{-} 1}+V_{e_{-} \max _{-} 2}+\ldots+V_{e_{-} \max _{-} i} \\
& -V_{e_{-} \min }>V_{e_{-} \max _{-} 1}=V_{e_{-} \max _{-} 2}=\ldots=V_{e_{-} \max _{-} i}
\end{aligned}
$$

(4) $i>1, j>1$ : In this case, i maximum and $\mathrm{j}$ minimum output current modules exist, whose equivalent circuit is shown in Fig. (7d). We get:

$$
\begin{aligned}
& \frac{V_{e_{-} \max 1}}{R_{s}}+\frac{V_{e_{-} \max \_}}{R_{s}}+\ldots+\frac{V_{e_{-} \max i}}{R_{s}}=-\frac{V_{e_{-} \min \_1}}{R_{s}} \\
& -\frac{V_{e_{-} \min \_} 2}{R_{s}}-\ldots-\frac{V_{e_{-} \min \_j}}{R_{s}} \\
& V_{e_{-} \max _{-} 1}+V_{e_{-} \max _{-} 2}+\ldots+V_{e_{-} \max _{-} i}=-V_{e_{-} \min _{-} 1} \\
& -V_{e_{-} \min _{-} 2}-\ldots . . .-V_{e_{-} \min _{-} j}
\end{aligned}
$$

This situation has multiple possibilities:

1. $i=j$

$V_{e_{-} \max _{-} 1}=V_{e_{-} \max _{-} 2}=\ldots=V_{e_{-} \max _{-} i}=$
$-V_{e_{-} \min _{-} 1}=-V_{e_{-} \min _{-} 2}=\ldots=-V_{e_{-} \min _{-} j}$

2. $i<j$

$V_{e_{-} \max _{-} 1}=V_{e_{-} \max _{-} 2}=\ldots=V_{e_{-} \max _{-} i}>$
$-V_{e_{-} \text {min } 11}=-V_{e_{-} \text {min }_{-} 2}=\ldots=-V_{e_{-} \text {min } \_j}$

3. $i>j$ 


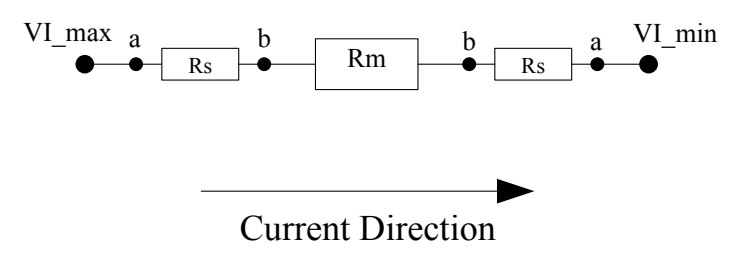

a)

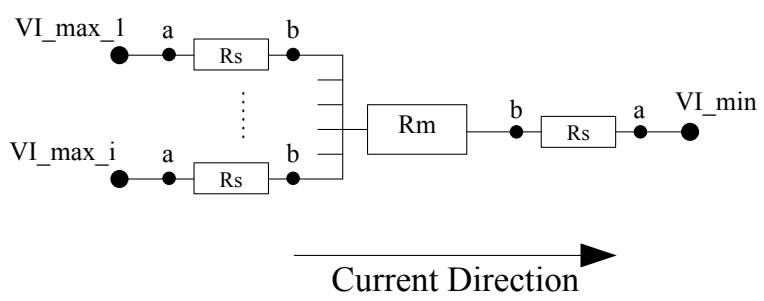

c)

Fig. (7). Extreme current selection circuit when.

a) $i=1, j=1$; b) $i=1, j>1$; c) $i>1, j=1$;d) $i>1, j>1$

$V_{e_{-} \max _{-} 1}=V_{e_{-} \max _{-} 2}=\ldots=V_{e_{-} \max _{-} i}<$

$-V_{e_{-} \min _{-} 1}=-V_{e_{-} \min _{-} 2}=\ldots=-V_{e_{-} \min _{-} j}$

Conclusion can be drawn from the analysis of 4 cases:

If $i>j$, as to say the number of maximum current modules is greater than minimum ones, the average current is close to maximum current. Extreme current selection circuit guarantees the current decrement of every maximum current module is smaller than the current increment of every minimum current module;

If $i<j$, as to say the number of minimum current modules is greater than maximum ones, the average current is close to minimum current. Extreme current selection circuit guarantees the current decrement of every maximum current module is greater than the current increment of every minimum current module;

If $i=j$, as to say the number of minimum current modules is equal to maximum ones, the average current is close to the average value of maximum and minimum current. Extreme current selection circuit guarantees the current decrement of every maximum current module is equal to the current increment of every minimum current module; current decrement of $i$ maximum current modules and current increment of $\mathrm{j}$ minimum current modules always keep equilibrium. In case of constant load, only $(i+j)$ modules with maximum or minimum current output are regulated, which reduces the regulating frequency of the entire system. Low frequency oscillation of output current is effectively avoided to improve system dynamic response.

To summarize, the most obvious feather of our method lies in that: through extremum value selection circuit, basic element with maximum and minimum output current is determined and regulated, and only the selected modules will be controlled. Detailed steps are described as follows:

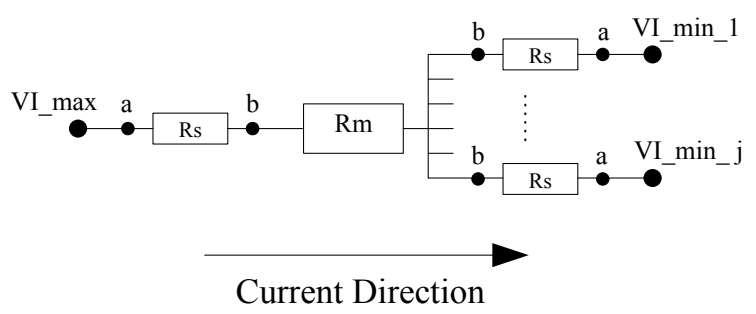

b)

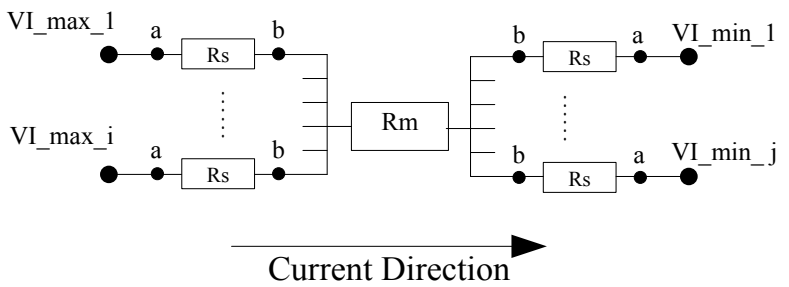

d)

1: Determine the given voltages of every element: $V_{r 1}=V_{r 2}=V_{r 3}=\ldots \ldots . .=V_{r n}$;

2: Obtain output current of elements through current detection circuit, which is converted into voltage signals representing current, and sent to the optocoupler of running/fault indicator;

3: If element operates at running state, the voltage $V_{I}$ becomes greater than zero and relay coil in running/fault indicator is on so that normally-open contacts of relay is closed. Running indicator is switched on while fault one is off, the element is regulated;

4: If element operates at fault state, the voltage $V_{I}$ stays around zero and relay coil in running/fault indicator is off so that normally-open contacts of relay is opened. Running indicator is switched off while fault one is on, the element will not be regulated;

5: $V_{I 1}, V_{I 2}, V_{I 3}, \ldots \ldots . V_{I n}$ from every element is sent to extremum value selection circuit, through which i elements with maximum current output and $\mathrm{j}$ elements with minimum current output will be determined by the buses;

6 : The voltage difference between $V_{I_{-} \max }$ and $V_{I_{-} \min }$ passes through resistor $R_{m}$ and $R_{s}$, and $\mathrm{V}_{\mathrm{e}_{-} \max }$ and $V_{e_{-} \min }$ are calculated as the voltage across $R_{s}$;

7: $V_{e_{-} \max }$ is transmitted current-sharing controller of the maximum current element to obtain given voltage difference $\Delta V_{r_{\max }}$. Then $\Delta V_{r_{\max }}$ as well as reference $V_{r}$ are sent to sum controller and control voltage $V_{r_{-} \max }{ }^{\prime}$ is calculated;

8: $V_{e_{-} \min }$ is transmitted current-sharing controller of the minimum current element to obtain given voltage difference $\Delta V_{r_{\text {min }}}$. Then $\Delta V_{r_{\text {min }}}$ as well as reference $V_{r}$ are sent to sum controller and control voltage $V_{r \text { min }}$ ' is calculated;

9: $V_{r_{-} \text {max }}$ ' is utilized to decrease the output current of maximum current element while $V_{r_{-} \text {min }}{ }^{\prime}$ is to increase the output 


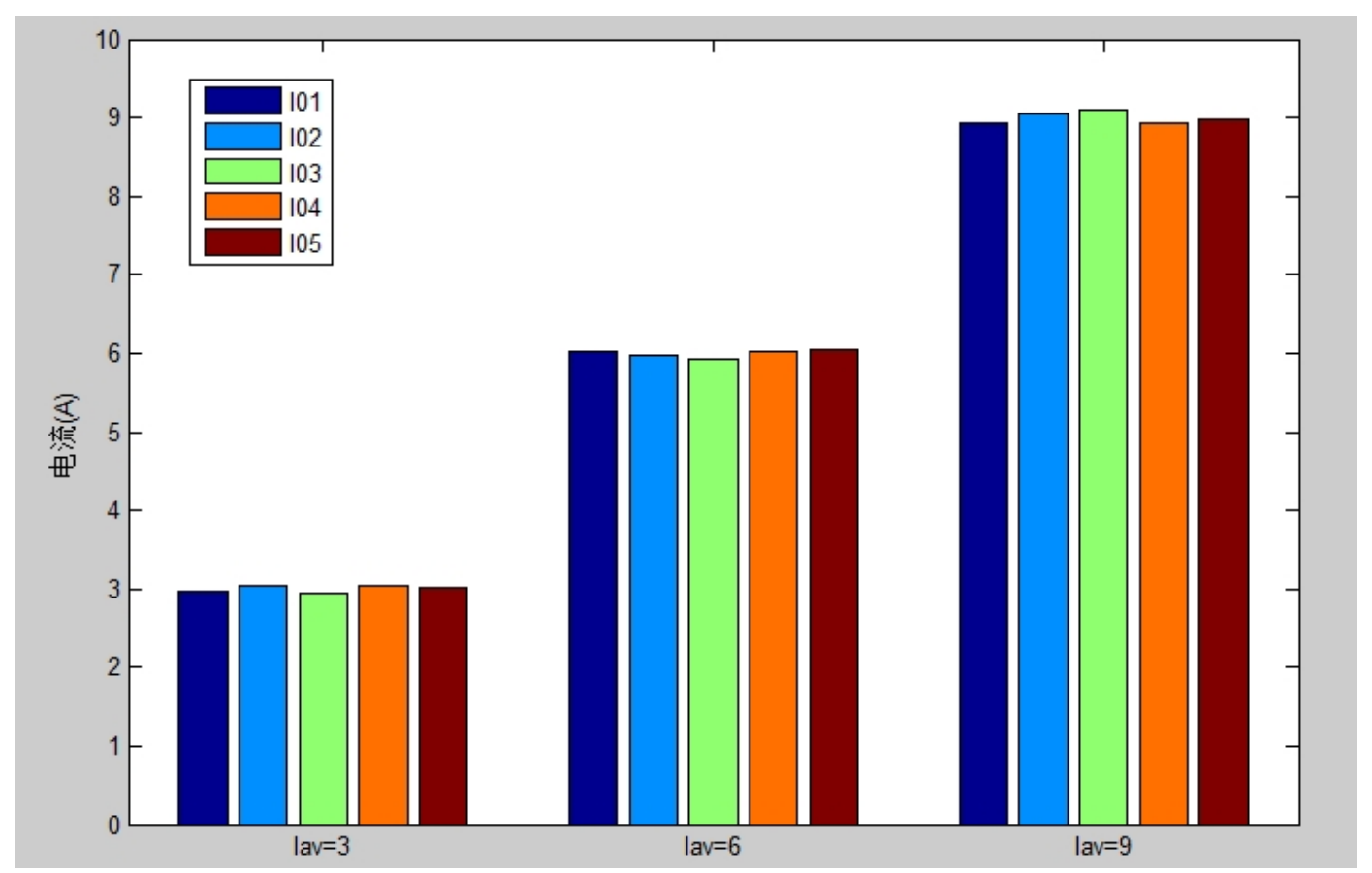

Fig. (8). Experimental data of current-sharing control.

Table 1. Experimental data of current-sharing control.

\begin{tabular}{|c|c|c|c|}
\hline & Load1 & Load2 & Load3 \\
\hline \hline $\mathrm{I}_{01} / \mathrm{A}$ & 2.97 & 6.02 & 9.04 \\
\hline $\mathrm{I}_{02} / \mathrm{A}$ & 3.06 & 5.98 & 9.06 \\
\hline $\mathrm{I}_{03} / \mathrm{A}$ & 2.95 & 5.93 & 8.92 \\
\hline $\mathrm{I}_{04} / \mathrm{A}$ & 3.04 & 6.03 & 8.99 \\
\hline $\mathrm{I}_{0} / \mathrm{A}$ & 3.01 & 6.06 & 45.1 \\
\hline $\mathrm{I}_{\mathrm{o}} / \mathrm{A}$ & 15.03 & 30.02 & 9.0 \\
\hline $\mathrm{I}_{\mathrm{av}} / \mathrm{A}$ & 3.0 & 6.0 & 0.17 \\
\hline $\mathrm{I}_{\text {error }} / \mathrm{A}$ & 0.09 & 0.11 & 1.89 \\
\hline error $/ 0$ & 3.0 & 1.83 & \\
\hline
\end{tabular}

current of minimum current element, which ensures the current decrement of all current modules is equal to the current increment so that other elements will not be affected. In this way, regulating frequency of system can be greatly reduced;

10: After the maximum and minimum elements are regulated, system will start to select new maximum and minimum elements and repeat the regulated process until output current of every element becomes balanced. Block diagram of proposed system is shown in Fig. (6).

\section{EXPERIMENTAL RESULT AND ANALYSIS OF CURRENT SHARING}

To validate the current-sharing control effect of multiple parallel power modules, experimental system with 5 switch power modules $(48 \mathrm{~V} / 10 \mathrm{~A})$ is designed in case of pure resis- tive load and measured currents through the load and every power module with oscilloscope. Experimental data are shown in Table 1. The currents after regulation are listed for comparison and in Fig. (8), a histogram is shown to give an intuitive view of results.

From the experimental data in Table 1, it's clear that the unbalanced degree with light load is about 3\% while 1.89 with heavy load. Unbalanced degree will be less than $5 \%$ with 15-45A load, whose data are not listed in this paper for space consideration. Results shown above realize auto current-sharing effectively with good accuracy and reliability.

\section{CURRENT AND FUTURE DEVELOPMENTS}

The paper has reviewed common parallel current-sharing control methods and recent related patent [16-19], and pre- 
sented a novel method. The extreme current selection circuit consists of resistors and diodes and selects maximum and minimum output current modules with buses. In this method proposed, only modules with maximum or minimum current output in current condition are regulated, which improves system dynamic response. Moreover, only hard distributed hardware such as resistor and diode are used to achieve current-sharing among parallel systems rather than intelligent controller (CPU) and complex programming, which greatly reduces the cost of power supply. Running/fault indicator of power module is provided for redundancy architecture. All these feathers ensure the leading position in current-sharing field of our method. Through current tuning, the effective current-sharing control is achieved. Finally experimental result demonstrates the good performance of our novel control strategy.

\section{CONFLICT OF INTEREST}

The authors confirm that this article content has no conflict of interest.

\section{ACKNOWLEDGEMENTS}

This work was supported in part by Natural Science Research Project of Education Department in Henan Province (2007510014).

\section{REFERENCES}

[1] X. S. Zhan, "Technique of parallel balanced current in smps", Agriculture and Technology, vol. 29, no. 3, pp. 136-138, 2009.

[2] Y. F. Gao, and X. J. Hu, "Parallel current-sharing system in blocking switch power supply", Chinese Journal of Power Sources, vol. 35, no. 2, pp. 210-212, 2011.

[3] Y. P. Zhong, and Z. C. Wei, "Study on Current Sharing of A Large Capacity Switching Power in Parallel", Power Electronics, vol.39, no. 6,2005 .

[4] S. L. Du, and P. Wang, "A control strategy for parallel current sharing technology in switching power supply", Chinese Journal of Power Sources, vol. 36, no. 7, pp. 1037-1038, 2012.
[5] Q. Zhang, and X. L. Yao, "Control circuit and method of parallel DC switch power source with double current-sharing buses," China Patent 200910073437, May 19, 2010.

[6] T. Y. Yang, "Power supply with current-sharing control and current-sharing method thereof," U. S. Patent 37,523,944, June 8, 2005.

[7] C. C. Hsu, and C. C. Yeh, "Power system with combination of active current sharing and droop current sharing and power system assembly using the same," U. S. Patent 50,099,567, January 2, 2013.

[8] K. Siri, "Current sharing power system," U. S. Patent 44,656,308, March 24, 2010.

[9] C. S. Lee, and S. C. Lee, "Current-sharing power supply apparatus with bridge rectifier circuit," U. S. Patent 43,756,483, September $18,2009$.

[10] K. J. Buterbaugh, "Dynamically configuring current sharing and fault monitoring in redundant power supply modules," U. S. Patent 41,567,989, April 30, 2012.

[11] C. S. Lee, and S. C. Lee, "Current-sharing power supply apparatus with bridge rectifier circuit," U. S. Patent 43,756,483, September $18,2009$.

[12] J. Barrenscheen, "System and method for transmitting current sharing information among paralleled power trains," U. S. Patent 42,221,080, December 19, 2008.

[13] J. B. Wang, R. Lo, and J. H. Chang. "Paralleled DC/DC Converter Via Primary Current Droop Current Sharing Control". In: International Conference on PEDS, 2009, pp. 1119-1124.

[14] J. Sun, and Q. Liu, "A Current Sharing Control Strategy Of Paralleled Dc/Dc Converter Based on Simple Model". In: International Conference on PEDS Optics, Photonics and Energy Engineering, 2010, pp. 288-291.

[15] C. H. Cheng, P. J. Cheng, and M. J. Xic, "Current sharing of paralleled dc/dc converters using ga-based pid controllers", Expert Systems with Applications, vol. 1, pp. 733-740, 2010.

[16] S. J. Guo, and B. Yi, "Current-sharing of paralleled control technology for improved switch power supply modules", Chinese Journal of Power Sources, vol. 37, no. 4, pp. 621-623, 2013.

[17] Y. Q. Liu, and S. X. Duan, "An improved current sharing control strategy for parallel inverter system", Power Electronics, vol. 41, no. 6, pp. 8-9, 26, 2007.

[18] Q. Zhang, and X. L. Yao, "Current sharing control in the parallel operation of dc power supplies", Power Electronics, vol. 45, no. 4, pp. 73-75, 2011.

[19] X. J. Zuo, and Y. Yang, "Design of parallel current-sharing in switch power supply", Journal of Qingdao University(Engineering \& Technology Edition), vol. 27, no. 3, pp. 42-45, 2012.

Received: September 22, 2014

(C) Wu et al.; Licensee Bentham Open.

This is an open access article licensed under the terms of the Creative Commons Attribution Non-Commercial License (http://creativecommons.org/licenses/by-nc/3.0/) which permits unrestricted, non-commercial use, distribution and reproduction in any medium, provided the work is properly cited. 